\title{
Una aproximación a la construcción de marca-ciudad como estrategia de inserción nacional e internacional
}

\section{An approximation to city branding as an strategy for national and international insertion}

\author{
Mariana Calvento \\ Maia OCHOTeco*
}

\begin{abstract}
In this work we analyse the feasibility of a regional brand and/or a city branding for the Argentine townships of Tandil, Olavarría and Azul (TOA). We analyse the assessment of the region's image in the largest media in Argentina. This work investigates the characteristics of one of the strategies carried out in Argentina as an alternative means of development for cities and regions.
\end{abstract}

Keywords: city branding strategy, local governments, regional brand, insertion and development strategies.

\section{Resumen}

La presente investigación analiza la factibilidad de construir una marca-regional y/o marca-ciudad para las localidades argentinas de Tandil, Olavarría y Azul (TOA). Para ello se analiza la valoración de la imagen de la región en los grandes medios gráficos argentinos. El trabajo propone indagar las particularidades de una de las estrategias llevadas a cabo en Argentina con la intención de funcionar como vía alternativa al desarrollo de ciudades y regiones.

Palabras clave: estrategia marca-ciudad, gobiernos locales, marca-regional, estrategias de inserción y desarrollo.

* Universidad Nacional del Centro de la Provincia de Buenos Aires, Argentina. Correos-e: marianacalvento@yahoo.com.ar, maiaochoteco@yahoo.com.ar. 


\section{Introducción}

En este trabajo nos proponemos indagar una de las estrategias de inserción internacional de los espacios locales, ${ }^{1}$ la marca-ciudad, así como analizar la factibilidad de construirla en los municipios de Tandil, Olavarría y Azul.

Con estos objetivos en mente, la investigación se estructura de la siguiente manera. En el primer apartado se desarrolla el actual escenario internacional y se investiga la inserción de los espacios locales en el contexto internacional, haciendo énfasis en la importancia que adquieren los mismos. En el segundo se refleja cómo estos cambios globales y locales repercutieron en Argentina y se reseñan experiencias concretas de inserción nacional e internacional por parte de los espacios locales, como la implementación de la marca-ciudad. En el tercer apartado se investiga el ámbito nacional profundizando en la factibilidad de establecer marca-ciudad o marca-regional en las ciudades de Tandil, Olavarría y Azul. En ese sentido, mediante un análisis comparativo se analiza la imagen que reflejan los medios gráficos sobre dichas ciudades. De esta manera se evalúa la valoración de la región mediante un seguimiento de las notas, noticias y crónicas que hacen referencia a las tres ciudades en los principales diarios del país.

\section{Escenario internacional y espacios locales}

La actualidad mundial presenta un escenario de cambios que se vienen desarrollando en los últimos años, algunos de los cuales aún se encuentran en transición. Parafraseando a Sandra Colombo (2006), estas transformaciones no son monotemáticas ya que atraviesan las esferas tecnológica, geopolítica, comercial, financiera, institucional, cultural y social.

Estos cambios se asociaron con una pérdida de poder y de autonomía de decisión de los Estados nacionales, condicionados, por un lado, por las restricciones que les imponían -en el nuevo marco global- la extrema concentración del poder económico en manos de las empresas y del capital financiero multinacionales, así como el protagonismo cada vez mayor de los organismos multilaterales y, por otro, por la fragmentación de las

${ }^{1}$ Con el término espacios locales se hace referencia a instancias gubernamentales subnacionales, por ejemplo, municipios para el caso de la provincia de Buenos Aires, Argentina. 
soberanías nacionales impulsadas por acentuados particularismos étnicos o culturales (Gilles, 1994). No obstante, hay corrientes de pensamiento que planean una revaloración del Estado, principalmente en el ámbito subnacional.

Hay distintas posiciones en relación con esta temática, ya que como señala Boisier, hay "quienes sostienen que la globalización devalúa el territorio y los que sostienen, por el contrario, una revalorización territorial en ella" (2005: 49).

Entre los primeros predomina la idea de que la globalización ha impulsado el predominio de las grandes corporaciones y que, por tanto, los espacios reducidos no tienen margen de maniobra. Por su parte, los segundos apoyan la posición de que la globalización libera tendencias que revaloran el territorio y que, en consecuencia, los lugares y las localidades ahora son más importantes para contribuir a la innovación y a la alta tecnología y, por tanto, al desarrollo.

La revaloración del territorio adquiere cada vez más adeptos, así como más pruebas que demuestran su importancia. Para esta línea de argumentación seguimos a Boisier (2005: 47-62), quien señala por lo menos tres características que hacen del territorio una herramienta que la globalización no ha vuelto anacrónica.

La primera hace referencia a un análisis, desde el punto de vista sociológico, que dice que las personas atraviesan la mayoría de las etapas de su vida en un territorio concreto de no más de $500 \mathrm{~km}$ de radio. Por tanto, según Boisier, "es fácil inferir que para cualquier individuo, la realización de su proyecto individual de vida depende críticamente de lo que acontezca a lo largo del tiempo en su entorno cotidiano" (2005: 50). De allí la clara identificación de los individuos con su territorio, y no su desprendimiento, como argumentan algunos autores.

La segunda característica se acerca más al plano tecnoeconómico. Las últimas transformaciones técnico-productivas ligadas a la revolución científica y tecnológica han llevado a "permitir la segmentación funcional y territorial de los procesos productivos sin pérdida de eficacia ni de rentabilidad" (Boisier, 2005: 50). De esta manera, la localización de las empresas ha llevado a valorar las condiciones de los territorios en los cuales se asientan, dando mayor importancia a las características propias del mismo, en las que se incluyen variables sociales, que antes no tomaban en cuenta estos análisis.

La última característica se acerca a variables culturales e identitarias. La globalización, que lleva al contacto de personas de 
diversas culturas, ha potenciado asimismo la búsqueda por preservar los valores que le confieren identidad a cada pueblo. Como señala Boisier, el hombre es un 'animal territorial' y tal característica de la persona humana aflora con fuerza en la contemporaneidad" (2005: 50).

De esta manera, y de acuerdo con Boisier, en el nuevo escenario internacional el territorio juega un papel más importante que en el pasado. Asimismo, autores como Arocena (2001) enfatizan la necesaria complementación entre el desarrollo local y la globalización "buscando formas de articulación local-global" (2001: 33), inclinándose también por la valoración de lo local.

\section{Lo local en Argentina y sus estrategias}

En Argentina, lo local empieza a revalorarse a raíz de los efectos de la implementación de políticas neoliberales. Estas políticas que comenzaron a aplicarse a partir de la década de los setenta son: la redistribución regresiva del ingreso, el ajuste del mercado de trabajo, la reasignación de recursos entre actores y sectores económicos, la apertura asimétrica al exterior, la liberalización de los mercados (sobre todo del financiero) y el aislamiento de la industria. Dichas políticas condujeron a redireccionar la tarea de asignación de recursos y de distribución del ingreso del Estado, con el fin de reforzar la centralización del capital y la concentración del ingreso.

La transformación económica, circunscrita a la incorporación de las medidas neoliberales, tomó mayor impulso cuando asumió el gobierno Carlos Menem. Durante dicha administración, Argentina no estuvo exenta del auge global del neoliberalismo, cuya corriente de pensamiento penetró a través del plan conocido como el Consenso de Washington. Éste se caracterizó por el conjunto de recomendaciones dadas a los países endeudados, sobre todo latinoamericanos, al momento de solicitar tanto renegociaciones de deudas como nuevos préstamos.

El gobierno de Menem encontró un campo externo e interno proclive a la implementación de políticas económicas neoliberales. Las mismas comenzaron a materializarse a partir de la sanción de dos leyes: la Ley 23.697, de Reforma del Estado que otorgaba la concesión de poderes al ejecutivo para intervenir las empresas públicas, modificar su funcionamiento y privatizarlas; y la Ley 23.696, de Emergencia Económica que derogaba el trato diferencial entre capital nacional y extranjero y también suspen- 
día los regímenes de promoción industrial, regional y de exportaciones. Por tanto, las políticas implementadas en el gobierno de Menem poseían tres ejes: la liberalización comercial (reducción de las barreras arancelarias y la eliminación de las paraarancelarias), la desregulación (eliminación del régimen de control de precios, de regulaciones para las inversiones extranjeras, etc.) y la privatización (de servicio públicos). Asimismo, durante este periodo se estableció una transformación de la relación Estado nacional-provincial-municipal a través de políticas de descentralización, donde los municipios debieron redefinir sus roles, muchas veces sin contar con las herramientas y capacidades institucionales y de gestión necesarias.

El primer periodo de gobierno de Carlos Menem (1989-1995) se caracterizó por un claro crecimiento económico. No obstante, esta etapa de bonanza se interrumpió bruscamente por los efectos de la crisis mexicana. Es en el segundo mandato menemista (1995-1999) que la situación toma otra dirección. Los efectos de las reformas y del ajuste que se venían ocultando salen a la luz al cortarse los capitales con la crisis 1994-1995. Entre los efectos se destacan las altas tasas de interés, las caídas del producto interno bruto (РІB), del consumo y de la inversión, el aumento del desempleo y el desequilibrio fiscal, entre otros.

A mediados de los noventa diversas variables presentaron signos negativos. Desde 1994, debido tanto a la recesión como a la caída de los salarios y el aumento del desempleo, la pobreza se acrecentó dramáticamente, alcanzando para 1996 niveles cercanos al 30\%. Susana Torrado señala que la excepcionalidad de este hecho se debió a que se produjo un momento de inflación nula y que, por tanto, "puede considerarse inherente a la naturaleza del modelo" (1999: 2).

Es en esta situación económica, social y política que se genera el espacio para el surgimiento de la iniciativa local. De allí que se produzcan nuevos enfoques para lograr un verdadero desarrollo territorial. En este marco se impulsa el enfoque de desarrollo local, que según Madoery surge a partir de una importante observación, particularmente en países desarrollados: "el desarrollo de muchas regiones que mejoraron su posición en la jerarquía espacial, ha sido parte de dinámicas específicas del territorio y no de fenómenos de redistribución” (1999: 3).

Arocena señala que estas iniciativas locales tuvieron ciertos obstáculos, como la situación económica del país y la “debilidad de las instituciones locales [...] principalmente de los municipios 
de ciudades medias y pequeñas" (2001: 11). Con eso hace referencia a la limitada posibilidad de influencia con que cuentan numerosos municipios del país y, por tanto, las dificultades que han enfrentado estas iniciativas. Sin embargo, se presentan excepciones notables que dejan de manifiesto la posibilidad de la iniciativa local en Argentina.

En ese sentido se podría afirmar que las experiencias de inserción internacional de los espacios locales son variadas. Los espacios locales o ciudades vienen estableciendo relaciones con otras ciudades o regiones del mundo y ven el intercambio en diversos ámbitos: comercial, cultural, educativo, tecnológico, de ayuda solidaria y colaboración.

El impulso que toman los espacios locales lo constata Petrantonio cuando afirma que ya a "mediados de la década pasada, comenzaron a encontrarse en Argentina ejemplos de municipios que iniciaron 'tibiamente' a definir una política exterior local” (2003: 15).

Hay diversos ejemplos de estrategias locales de inserción internacional, entre los que se pueden destacar el hermanamiento de ciudades, las mercociudades, etc. Otro tipo de estrategia de inserción nacional, pero también internacional, que tomamos como caso de estudio para esta investigación es la de marcaciudad, que cuenta con el antecedente de la elaboración de marcas públicas en el país. Esta estrategia se fundamenta en el actual mundo globalizado que ha generado un creciente interés respecto de políticas de imagen por parte de los países.

En la región latinoamericana se han dado pasos en esta dirección. Países como Costa Rica, Ecuador, Chile, México, Brasil y Argentina, entre otros, han desarrollado políticas activas destinadas a mejorar su imagen exterior mediante la construcción e implementación de marca-país.

La mayoría de estas marcas apuntan a potenciar ámbitos económicos, culturales, atractivos para inversionistas, turistas y otros con el fin de posicionar al país en cuestión en el escenario internacional. Así, se encuentran aquéllas que apuntan únicamente al turismo, otras que buscan potenciar sus sectores exportadores y algunas más que se abocan a estructurar una marca-país integral que abarque la promoción del turismo, la industria, el comercio exterior, la cultura, la tecnología, etcétera.

En Argentina, luego de la crisis de los años 2001-2002, se comienza a hablar de la necesidad inminente de mejorar la imagen para lograr una reinserción efectiva del país en el sistema interna- 
cional. El gobierno definió la estrategia marca-país como "la utilización de los factores diferenciales de la Argentina -personajes, lugares, productos, submarcas, actividades, entre otros- con la finalidad de posicionarla en el concierto internacional, aumentando y diversificando el turismo, las exportaciones y las inversiones, y difundiendo nuestra cultura y deporte, tanto en calidad como en cantidad" (Presidencia, 2004: 12). En ese sentido, la estrategia incluye una visión integral para potenciar el turismo, las exportaciones, las inversiones, la cultura, el deporte y la ciencia.

La marca-país argentina no se limita el ámbito meramente nacional, sino que busca abarcar un mayor espectro. Se considera que esta estrategia vendría a potenciar o, en su caso, estimular marcas de regiones, provincias y municipios.

En este marco se inserta la implementación de las estrategias marca-ciudad, cuyos ejemplos encontramos en numerosos casos. Según Agüero et al., la marca-ciudad es "un activo altamente estratégico para potenciar los valores culturales, los negocios turísticos y comerciales de una ciudad" (2006: 21).

En la actualidad una marca se constituye en un valor agregado cuando las percepciones sobre un país, región o ciudad son positivas, lo que propicia una impresión favorable de las marcas de productos fabricados en ese lugar y potencia toda una serie de actividades.

En Argentina se pueden ver casos de este tipo de estrategia. Un ejemplo es el de la ciudad de Villa Gesell, que entre 2003 y 2004 comenzó a preparar su marca. Según el informe "Construcción de la Marca-Ciudad de Villa Gesell" (Management Político, 2004), la misma se encargó de descubrir las bases de la identidad de la ciudad y definir sobre qué atributos se construiría su marca.

Asimismo, en el proceso de creación se buscó una clara participación de los habitantes de la ciudad para lograr consenso y participación. Por último, y ya con una marca establecida, se procedió a realizar una campaña publicitaria integral.

La estrategia de Marca-Ciudad Villa Gesell se incluye en el Plan Estratégico Villa Gesell, Municipalidad de Villa Gesell-Universidad Nacional de La Plata, Buenos Aires, Argentina, 2002, donde se señala como uno de los objetivos principales "Preservar, fortalecer y potenciar la marca "Villa Gesell'". A través de esta marca pública se busca "atraer turismo del país y del Mercosur durante todo el año, promover inversiones y colaborar con el desarrollo de la producción local” (Management Político, 2004: 209). 
Como Villa Gesell, otras ciudades del país se encuentran en proceso de construcción e implementación de marcas. En ese sentido, Tandil, Olavarría y Azul representan una potencial marca-regional o futuras marca-ciudad.

Para ello examinamos la factibilidad de establecer marca-ciudad o marca-regional en estas ciudades, mediante un análisis comparativo sobre la imagen que reflejan en los medios gráficos.

\section{Análisis comparativo de la imagen de Tandil, Olavarría y Azul}

En este apartado se analiza la valoración y percepción de la imagen de la región en los grandes medios gráficos del país. El estudio abarca cinco años (2001-2005) y se fundamenta en la presencia de notas de opinión, noticias y crónicas que hacen referencia a las ciudades de Tandil, Olavarría y Azul.

La investigación busca evaluar la percepción externa de la imagen de estas ciudades a fin de convertirse en una herramienta útil para crear una estrategia de marca-regional y para el desarrollo e implementación de políticas de imagen. Nuestro objetivo es hacer un diagnóstico de la imagen de las ciudades de la región en la prensa nacional, mediante un seguimiento, clasificación, valoración y análisis de las noticias para identificar aquellos atributos -positivos o negativos- que se asocian a la región, a través de las diversas temáticas a las que las noticias hacen referencia, los lugares más destacados, las personalidades más reconocidas y representativas de cada ciudad, marcas, empresas, proyectos, actividades, servicios, etcétera.

El motivo de la elección de diarios nacionales para dicho análisis es que éstos se pueden considerar generadores y/o formadores de opinión. La noticia es uno de los elementos que conforma y afecta la imagen que se tiene de un país, ciudad o región. Como menciona la empresa GlobalNews, ${ }^{2}$ el hecho de que se publique una noticia del lugar o tema analizado indica que se le dio un valor de preferencia e interés a esa información, en lugar de otra. Este hecho hace relevante establecer una cuantificación de las noticias aparecidas en estos medios a lo largo de un periodo determinado porque, más allá de que una imagen no se construya a

${ }^{2}$ GlobalNews es un Grupo Consultor de los Medios de Comunicación Internacionales que ofrece servicios de clipping digital, inteligencia corporativa y análisis mediáticos de la prensa escrita, radio y televisión de todo el mundo. La empresa ha realizado trabajos de asesoría para implementar la Estrategia Marca Argentina. 
partir de noticias, lo publicado incide fuertemente en la imagen que se pretende construir.

Para este estudio se escogieron los diarios La Nación, Clarín $y$ Pagina/12 porque son los de mayor tirada a nivel nacional, los más consultados y porque analizan la información de manera más completa. ${ }^{3}$ El criterio que utilizamos para seleccionar la información se basó en toda aquella noticia que mencione a las ciudades o a la región, directa o indirectamente, y que se haya publicado en el cuerpo principal del diario o en suplementos. El análisis de las notas se organizó por ciudad y éstas se clasificaron por temas englobados en siete grandes grupos. Para lograr una visión integral, en el estudio de cada ciudad se incluyen las notas de los tres diarios. Éstas se dividen en:

- Turismo

- Patrimonio histórico-cultural

- Economía y sociedad

- Actividades de ciencia y tecnología

- Actividades culturales

- Actividades deportivas

- Personalidades reconocidas

\subsection{Tandil}

Como se observa en los temas más considerados por la prensa nacional (gráfica I), en la ciudad de Tandil, entre 2001 y 2005, se publicó un alto número de notas sobre turismo (102), ${ }^{4}$ seguido por personalidades reconocidas y deportes $\left(93^{5}\right.$ y $60,{ }^{6}$ respectivamente).

En el caso del turismo, la temática se desarrolla de manera muy diversificada y se observa un crecimiento continuo durante el periodo analizado (gráfica II). Las notas sobre turismo y personalidades reconocidas representan $27 \%$ y $25 \%$, respectivamente, les sigue en un porcentaje más bajo deportes (16\%) y en un tercer lugar, en un nivel parejo, se encuentran las notas sobre eco-

${ }^{3}$ Clarín es hoy uno de los diarios de mayor circulación en el mundo de habla española. Tiene una tirada promedio diaria de 400,000 ejemplares y es el de mayor tirada en Argentina. La Nación tira un promedio de 160,000 ejemplares, lo que lo convierte en el segundo diario argentino. En el caso de Página/12, su tirada promedio diaria es de 77,000 ejemplares.

${ }^{4}$ Números totales sobre un universo de 371 (100\%) notas.

${ }^{5}$ Idem.

${ }^{6}$ Idem. 
nomía y sociedad (11\%), cultura (8\%), ciencia y tecnología (7\%) y patrimonio histórico-cultural (6\%) (gráfica III). El posicionamiento de estos temas coincide de manera notable en los tres diarios analizados (gráfica IV).

De los diarios seleccionados, La Nación es el que mayor cantidad de notas publicó sobre Tandil (53\%), seguido por Clarín (39\%) y, en menor medida, Página/12 con 8\% (gráfica v).

En cuanto al turismo, la temática se desarrolla de manera muy diversa, si bien permanece como una constante la referencia de la ciudad como destino para fechas tradicionales como Semana Santa. Se destacan fundamentalmente las notas acerca del progresivo crecimiento del turismo nacional en distintas épocas del año y la diversificación y elección de destinos no tradicionales por parte de los turistas, hecho en el que Tandil se ve sumamente beneficiada. Se resalta la elección o preferencia de turistas por visitar la ciudad cada vez con mayor frecuencia, así como la opción de radicar en ella de manera definitiva. En un contexto de auge o tendencia del turismo rural, de descanso y de aventura, la prensa nacional destaca que Tandil se convierte en sinónimo de todos ellos, explotando, además, su punto fuerte en la gastronomía típica de la región y los productos artesanales. La referencia de la ciudad como símbolo de las sierras bonaerenses es una constante en las notas relacionadas con el turismo. Se hace especial hincapié en el paisaje serrano, la diversidad de opciones para actividades en la naturaleza, los paseos entre las sierras y la variedad de cerros explotados turísticamente.

En patrimonio histórico-cultural se mencionan lugares típicos de la ciudad, algunos de los cuales han sido restaurados y/o explotados turísticamente. Si bien la gran mayoría de ellos está estrechamente relacionada con el turismo, debido al importante número de notas que destacan el patrimonio de la región como uno de los puntos más fuertes, la temática merece tener entidad aparte. En el periodo analizado, los diarios hacen gran hincapié en lo que respecta a protección y/o valorización del patrimonio histórico-cultural de la ciudad.

En actividades deportivas, los diarios destacan la ciudad porque ha sido elegida por diferentes equipos de futbol como destino para prácticas de pretemporada y torneos, así como por las actividades deportivas que se organizan.

En el punto personalidades reconocidas se mencionan personajes de la ciudad, por una parte vinculados al ámbito artístico-cultural y que se consideran representativos de la ciudad; y por otra, 
deportistas importantes que han ido creciendo en diferentes disciplinas y que se les reconoce nacional e internacionalmente.

En el tema economía y sociedad, en los últimos cinco años las notas hacen referencia a la diversidad de actividades económicas e industriales de la ciudad y los casos de microproyectos exitosos y de empresas de Tandil que exportan a distintas partes del mundo. Por otra parte, a partir del crecimiento turístico y de servicios que comienza a experimentar la ciudad en los últimos años, las notas señalan el crecimiento demográfico-edilicio, a partir de los nuevos proyectos urbanos, así como los debates y críticas ante la necesidad de una mejor planificación.

En actividades culturales se menciona su crecimiento y desarrollo, especialmente en los últimos años. Los diarios destacan la industria educativa y cultural de Tandil por su calidad y potencialidades, la cual genera importantes actividades.

En ciencia y tecnología, se menciona la ciudad especialmente por el polo tecnológico al que se le está dando impulso, cuyo objetivo es articular el desarrollo empresarial con el conocimiento de la universidad. Se informa que en la actualidad Tandil es una importante cuna de la industria argentina de software. A su vez, se mencionan los casos de empresas y entidades que se destacan en el ámbito científico-tecnológico.

$\mathrm{Al}$ analizar la evolución de las noticias publicadas por año, se ve claramente un crecimiento progresivo y continuo entre 2001 y 2005, el cual ha llegado duplicarse. El año 2004 se destaca porque marca el mayor crecimiento en la evolución del periodo analizado (gráfica vI).

\subsection{Olavarría}

Al observar las temáticas más destacadas en la prensa nacional (gráfica VII), en la ciudad de Olavarría las notas ${ }^{7}$ sobre actividades deportivas son indiscutiblemente las que más se mencionan, mientras que el resto muestra un nivel bastante inferior, pero relativamente más parejo. El posicionamiento de las temáticas coincide mayoritariamente en los tres diarios.

En el periodo analizado este sector representa 64\%, seguido en un nivel mucho menor por las notas sobre economía y sociedad (18\%), luego las relativas a actividades culturales (8\%), seguido por turismo y actividades de ciencia y tecnología, ambas

${ }^{7}$ Universo de notas para la ciudad de Olavarría en la prensa nacional entre los años 2001-2005: 84 (100\%). 


\section{Gráfica I}

Tandil: número de notas por diario y tema (2001-2005)

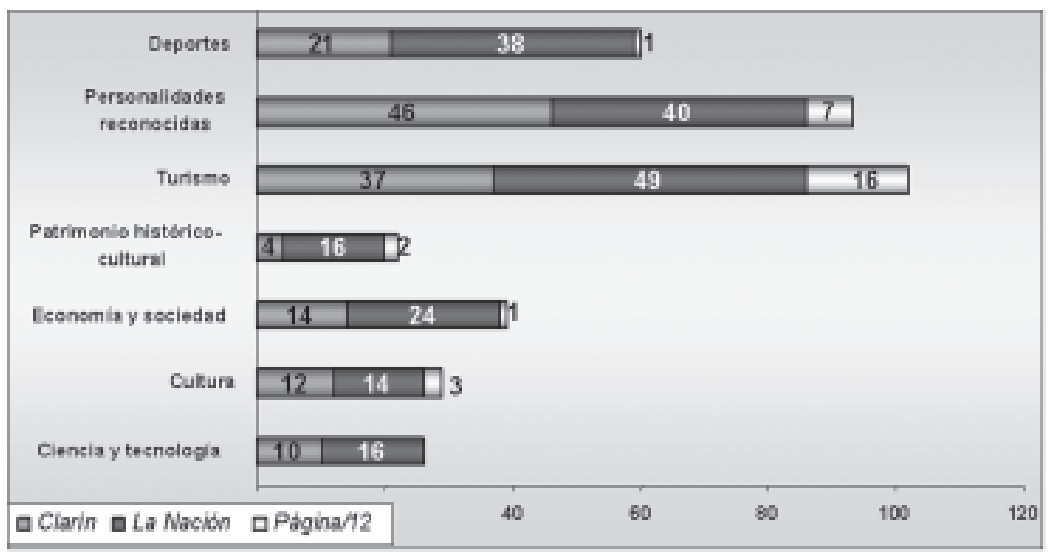

Fuente: Elaboración propia con base en datos de los diarios Clarín, La Nación y Página/12.

\section{Gráfica II}

\section{Tandil: notas sobre turismo (2001-2005)}

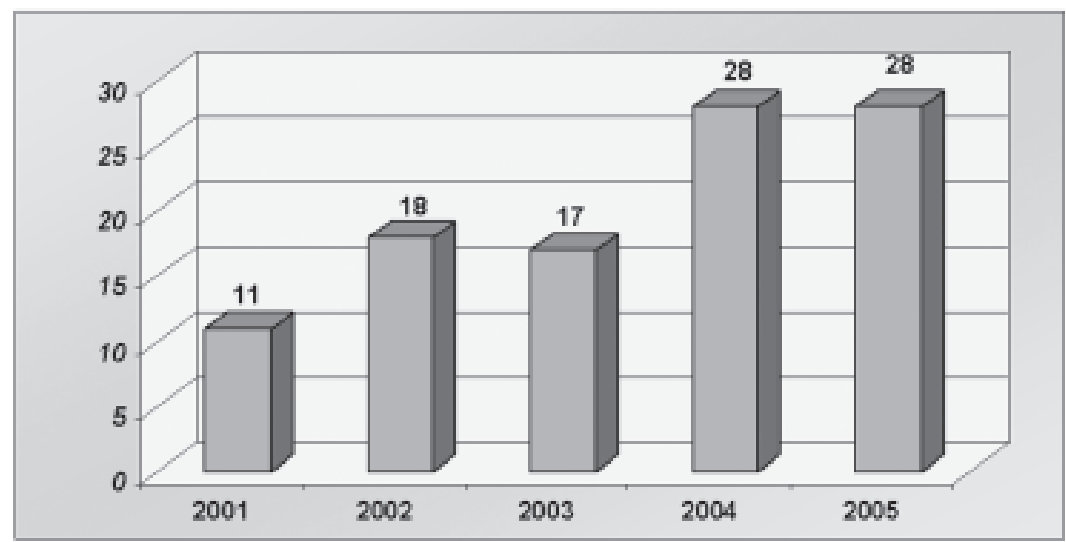

Fuente: Elaboración propia con base en datos de los diarios Clarín, La Nación y Página/12. 


\section{Gráfica III}

\section{Tandil: porcentaje por temática (2001-2005)}

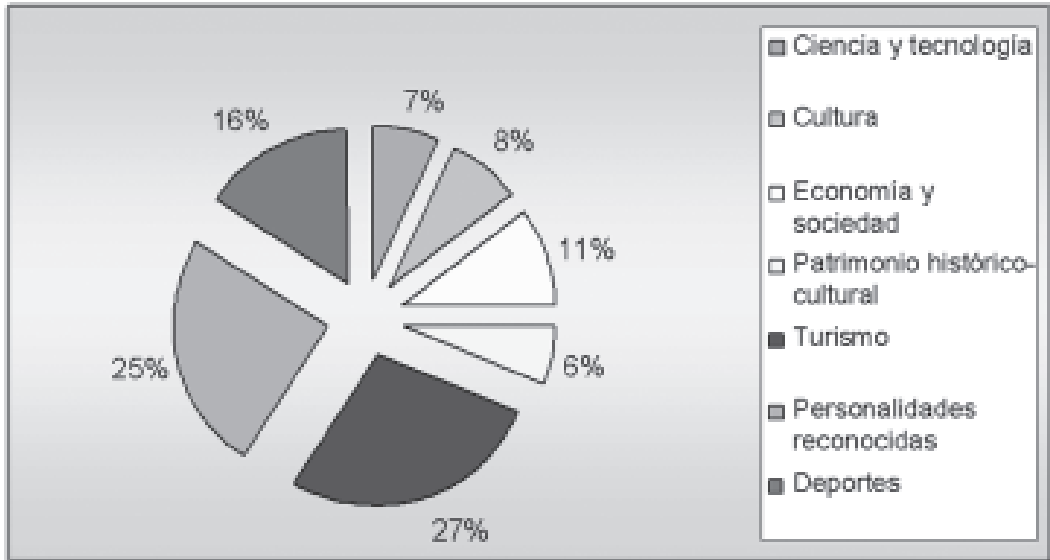

Fuente: Elaboración propia con base en datos de los diarios Clarín, La Nación y Página/12.

Gráfica IV

Tandil: notas por diario y tema (2001-2005)

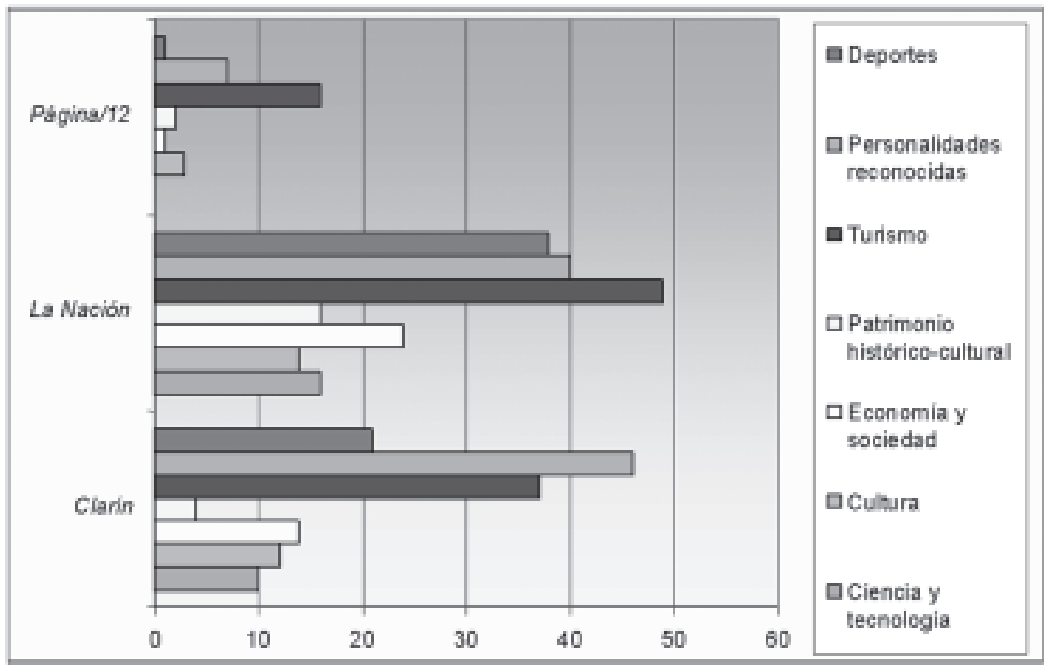

Fuente: Elaboración propia con base en datos de los diarios Clarín, La Nación y Página/12. 


\section{Gráfica V}

Tandil: total de notas por diario

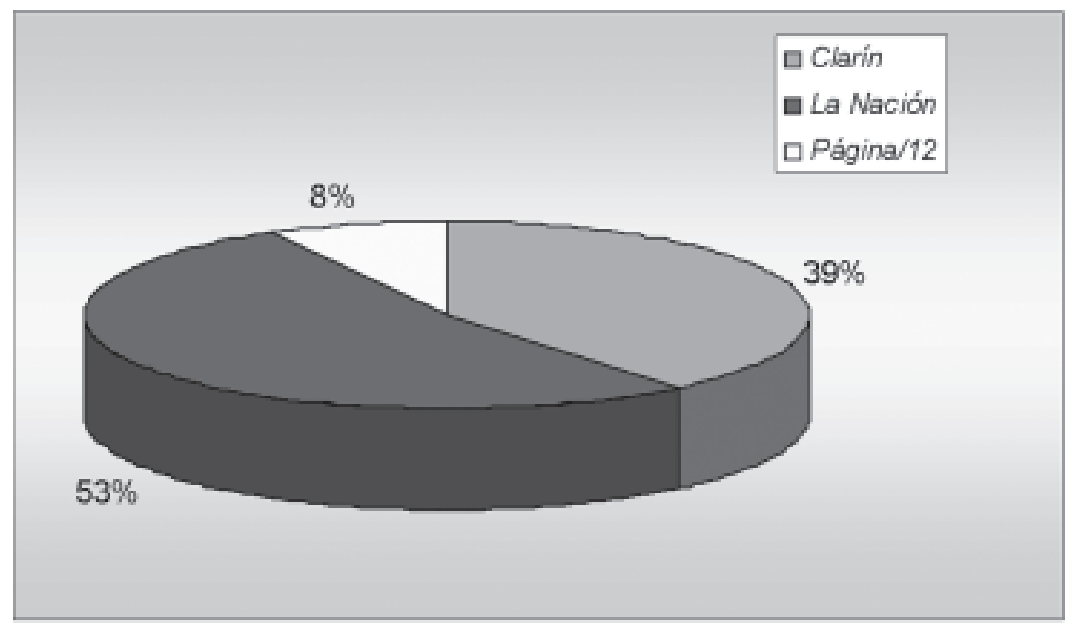

Fuente: Elaboración propia con base en datos de los diarios Clarín, La Nación y Página/12.

\section{Gráfica VI}

\section{Tandil: Cantidad total de notas por año}

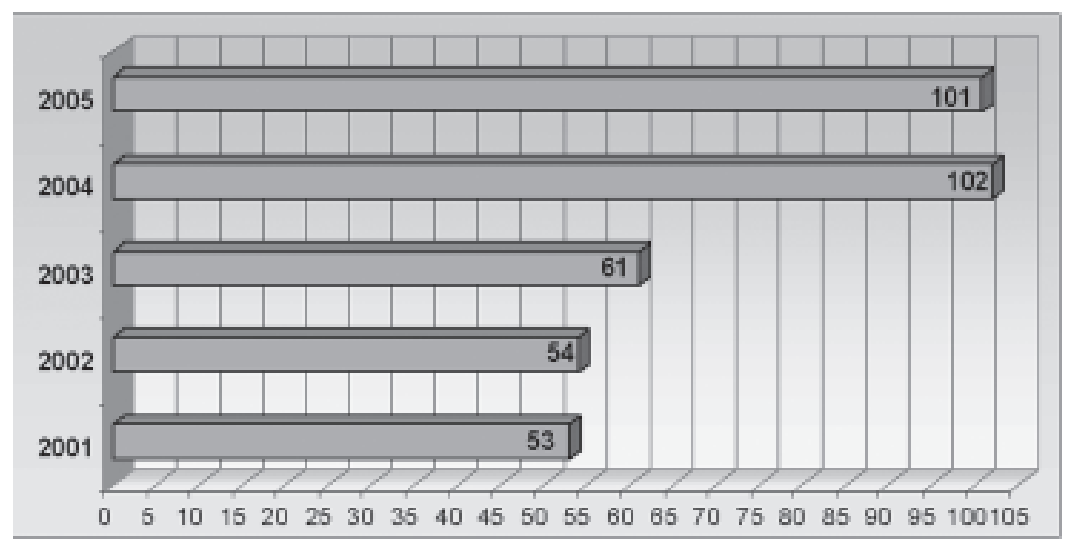

Fuente: Elaboración propia con base en datos de los diarios Clarín, La Nación y Página/12. 
con 4\%, y patrimonio histórico-cultural con $2 \%$. En el caso de Olavarría, no hay notas referidas específicamente a personalidades reconocidas, sólo se mencionan algunos personajes en notas generales (gráfica VIII).

A diferencia de la ciudad de Tandil, las notas sobre turismo no sólo no son las más mencionadas, sino que apenas se publican en los últimos dos años del periodo analizado (gráfica IX).

Como se observa en la cantidad de notas publicadas sobre Olavarría por diario, La Nación y Clarín mantienen una distribución pareja, con 44\% y 43\%, respectivamente, y en menor medida, Página/12, con 13\% (gráfica x).

En turismo la ciudad se menciona porque tiene una oferta turística basada en la historia, con sus pueblos picapedreros y estancias centenarias, así como circuitos para el turismo de aventura, minero y rural, entre sierras y canteras.

Como se menciona en el caso de la ciudad de Tandil, los puntos destacados en patrimonio histórico-cultural se valoran y explotan turísticamente, pero por su importancia en la región se señala en un punto separado del turístico.

En actividades de ciencia y tecnología, en materia de descubrimientos científicos, las investigaciones y hallazgos arqueológico-paleontológicos es el campo más destacado en esta ciudad.

En actividades deportivas se mencionan al Autódromo Sudamericano y el Club Estudiantes, como orgullos del deporte de la ciudad, así como los éxitos del equipo de baloncesto Estudiantes de Olavarría.

En el aspecto economía y sociedad se mencionan casos de microproyectos de la ciudad, así como la importancia de la fábrica cementera Loma Negra como uno de los símbolos de Olavarría. En personalidades reconocidas se destacan algunos personajes del ámbito deportivo y económico.

Respecto de la evolución de las notas por año, a diferencia de la ciudad de Tandil, en Olavarría se menciona un número importante de notas en los años 2001 y 2005, y en menor grado para los años 2002, 2003 y 2004. Esto refleja claramente la influencia que ejercen el gran número de notas deportivas sobre el resto, las cuales mayoritariamente se destacan en los años 2001 y 2005 (gráfica XI). 


\section{Gráfica VII}

Olavaría: número de notas por diario y tema (2001-2005)

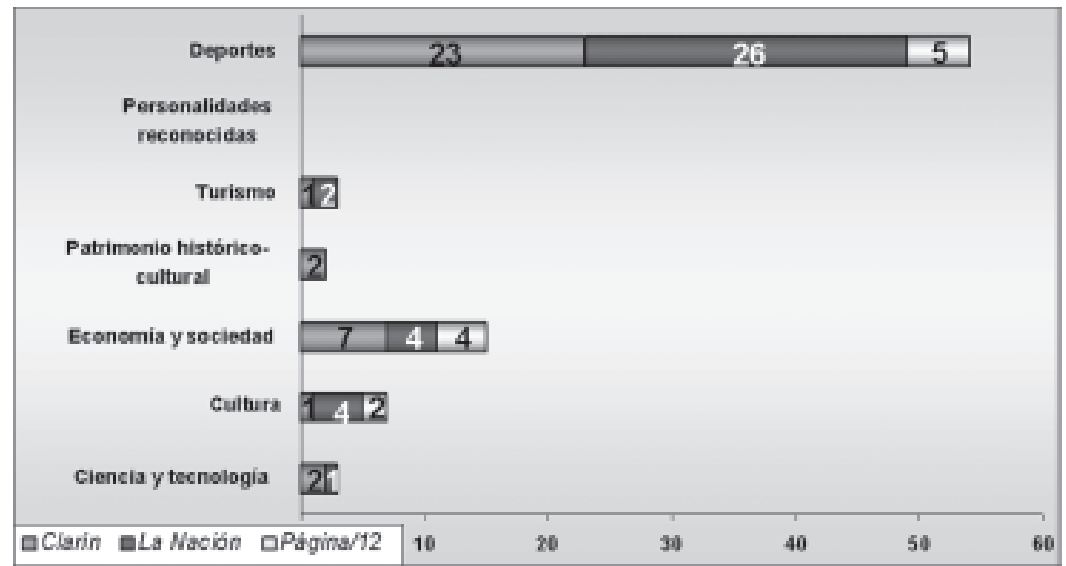

Fuente: Elaboración propia con base en datos de los diarios Clarín, La Nación y Página/12.

\section{Gráfica VIII}

\section{Olavaría: porcentaje por temática (2001-2005)}

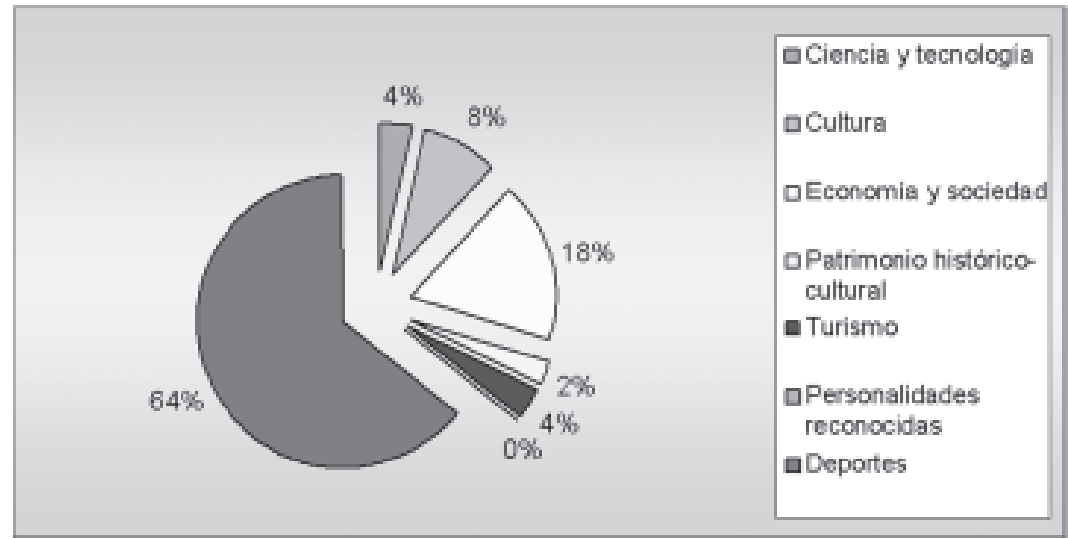

Fuente: Elaboración propia con base en datos de los diarios Clarín, La Nación y Página/12. 
Gráfica IX

Olavaría: notas sobre turismo (2001-2005)

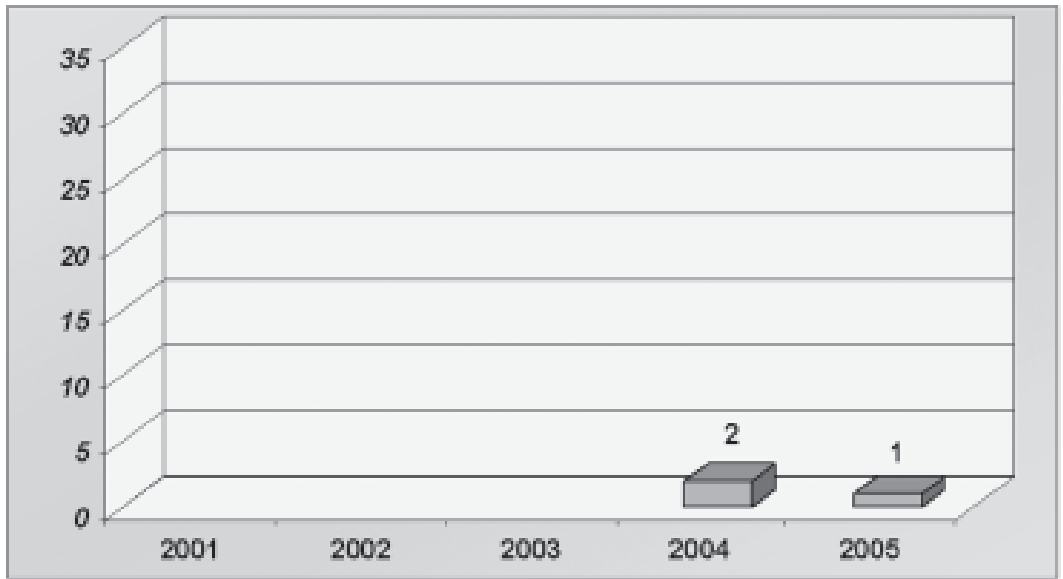

Fuente: Elaboración propia con base en datos de los diarios Clarín, La Nación y Página/12.

\section{Gráfica X}

Olavaría: total de notas por diario

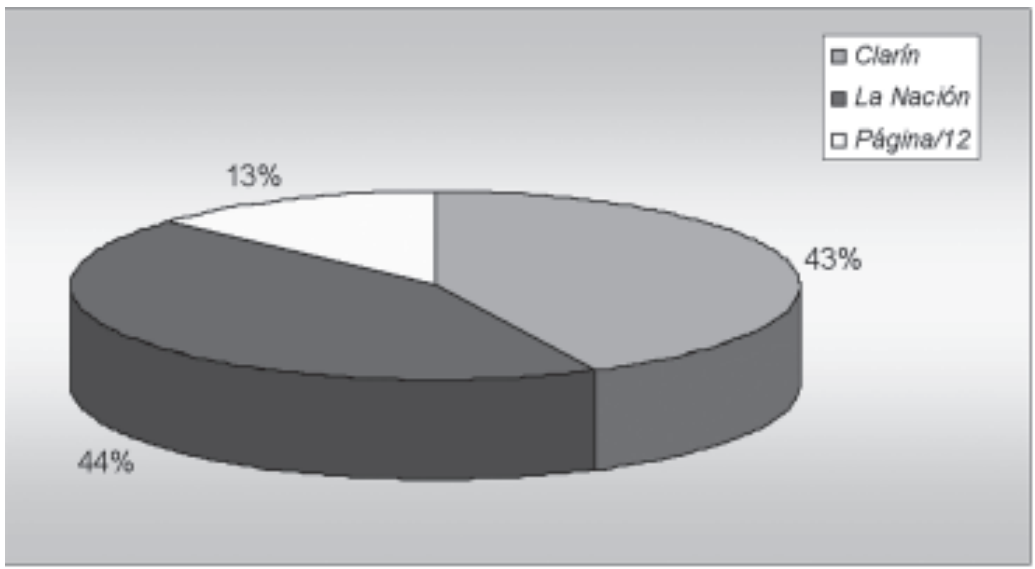

Fuente: Elaboración propia con base en datos de los diarios Clarín, La Nación y Página/12. 


\section{Gráfica XI}

\section{Olavaría: cantidad total de notas por año}

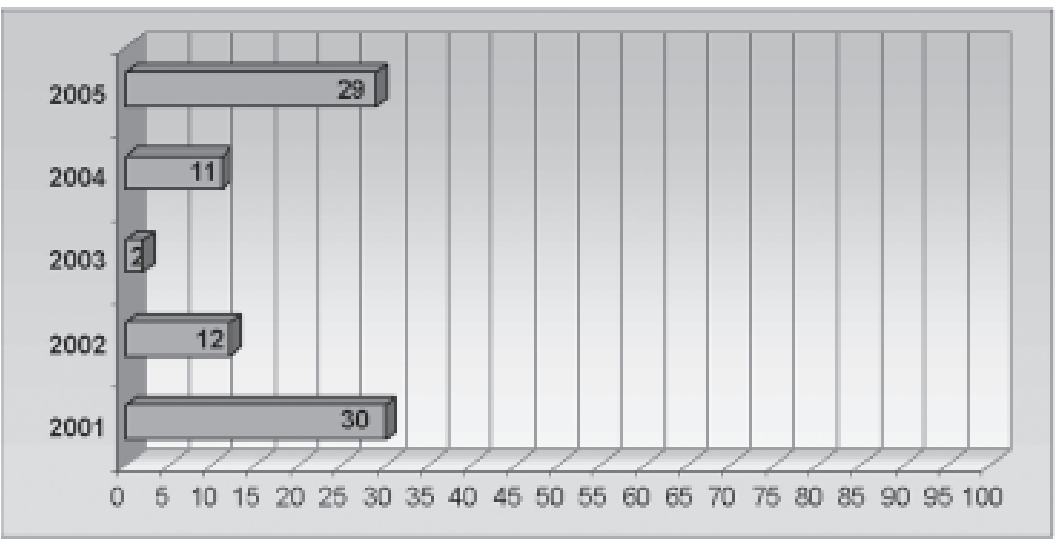

Fuente: Elaboración propia con base en datos de los diarios Clarín, La Nación y Página/12.

\subsection{Azul}

$\mathrm{Al}$ analizar las temáticas más destacadas por la prensa nacional sobre la ciudad de $\mathrm{Azul}^{8}$ (gráfica XII), sin duda las notas de actividades deportivas y las relativas a economía y sociedad son las que más se publican en los diarios analizados, representando 38\% y $37 \%$, respectivamente, seguido en menor medida por el sector actividades culturales y por las notas sobre patrimonio históricocultural, con $9 \%$ y $8 \%$, respectivamente, y luego por turismo y personalidades reconocidas, ambas con $4 \%$.

$\mathrm{Al}$ igual que la ciudad de Olavarría, el sector turístico es uno de los menos mencionados en la prensa nacional (gráfica XIII). Para el caso de la ciudad de Azul, no hay notas que hagan referencia a actividades de ciencia y tecnología (gráfica XIV).

Como en los casos de Tandil y Olavarría, con la ciudad de Azul La Nación nuevamente es el diario que mayor cantidad de notas publica, representando $49 \%$ en el periodo analizado, seguido por Clarín con 45\% y después Página/12, con 6\% (gráfica Xv).

En turismo, como en el caso de la ciudad de Olavarría, Azul se destaca como parte de un circuito que ofrece atractivos históricos, turísticos y de aventura. Se puede visualizar que Azul es un objetivo de turistas de fin de semana o parada en medio de un viaje mayor.

${ }^{8}$ Universo de notas para la ciudad Azul en la prensa nacional entre los años 20012005: $78(100 \%)$. 
La prensa nacional destaca que esta ciudad, como en las otras dos de la región analizada, posee un importante patrimonio histórico-cultural que también es una de las ofertas más interesantes para el turismo.

En el ámbito económico, la base agropecuaria de Azul sobresale en las notas referidas a la variedad de exposiciones que se desarrollan en la ciudad. Por su parte, en actividades deportivas los diarios destacan los éxitos de su equipo de voleibol, Olympikus.

En el punto personalidades reconocidas se mencionan personajes de la ciudad, por una parte vinculadas con el ámbito artístico-cultural y con el deportivo, considerados personajes representativos de la ciudad.

$\mathrm{Al}$ analizar la evolución de las notas publicadas por año, como en el caso de Olavarría, el tema predominante en todos los años es el deportivo, relacionado con los éxitos de los equipos de voleibol. En el sector relativo a economía y sociedad, se destacan notas de interés general. El resto de las noticias se mantiene en un nivel parejo (gráfica XVI). De esta manera, no se denota, como en el caso de Tandil, una evolución progresiva de la cantidad de notas por año, sino que durante el periodo analizado se mantienen en un nivel estable.

\subsection{La región}

Respecto de la cantidad de notas publicadas por ciudad (gráfica XVII), en el periodo analizado claramente Tandil es la ciudad que más se destaca, pues llega a cuadruplicar a Olavarría y Azul, cuyas notas son bastante inferiores en número, pero mantienen un nivel muy parejo.

Al observar la cantidad de notas publicadas por año (gráfica XVIII), la región muestra un crecimiento en los últimos dos años (2004-2005), a diferencia de los años 2001, 2002 y 2003. Si bien este hecho, en gran medida, está influenciado por el fuerte crecimiento en las notas sobre turismo y deportes, a partir de 2004 la prensa nacional refleja una importante diversificación en las notas publicadas sobre la región.

Analizando las temáticas publicadas en la región (gráfica XIX), las actividades deportivas es uno de los rubros más destacados en los cinco años, seguido por el turismo y por personalidades reconocidas (especialmente en el sector deportivo), todos en progresivo crecimiento en el periodo analizado. El sector referido a economía y sociedad es otro de los destacados y en un nivel infe- 


\section{Gráfica XII}

Azul: número de notas por diario y tema (2001-2005)

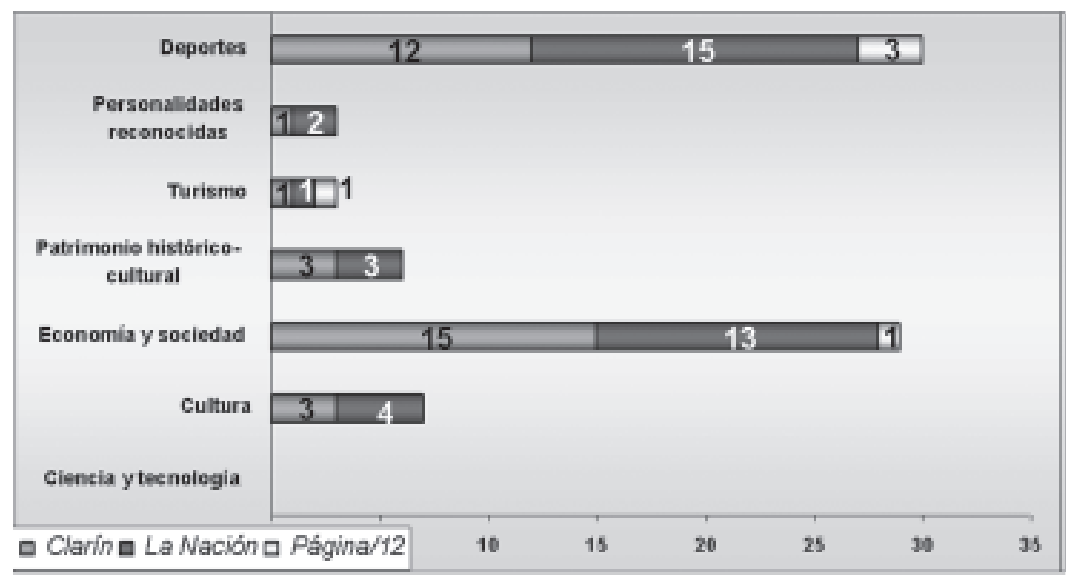

Fuente: Elaboración propia con base en datos de los diarios Clarín, La Nación y Página/12.

\section{Gráfica XIII}

Azul: notas sobre turismo (2001-2005)

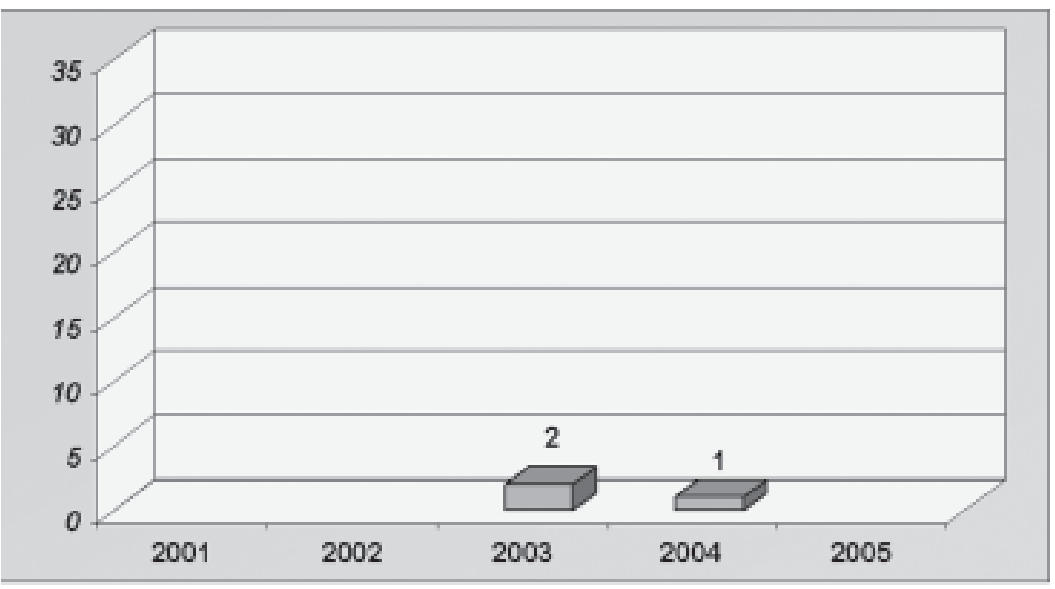

Fuente: Elaboración propia con base en datos de los diarios Clarín, La Nación y Página/12. 


\section{Gráfica XIV}

\section{Azul: porcentaje por temática (2001-2005)}

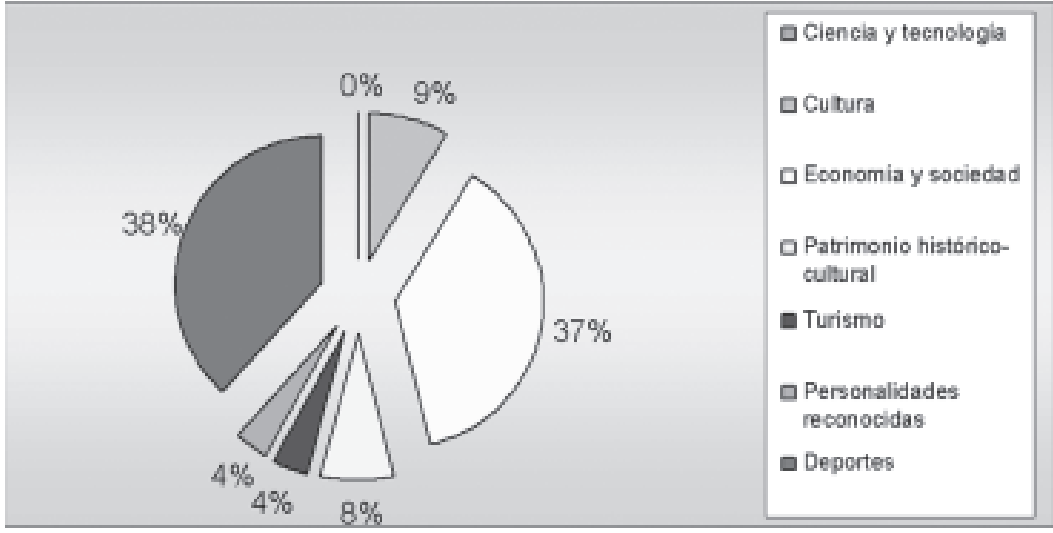

Fuente: Elaboración propia con base en datos de los diarios Clarín, La Nación y Página/12.

\section{Gráfica XV}

Azul: total de notas por diario

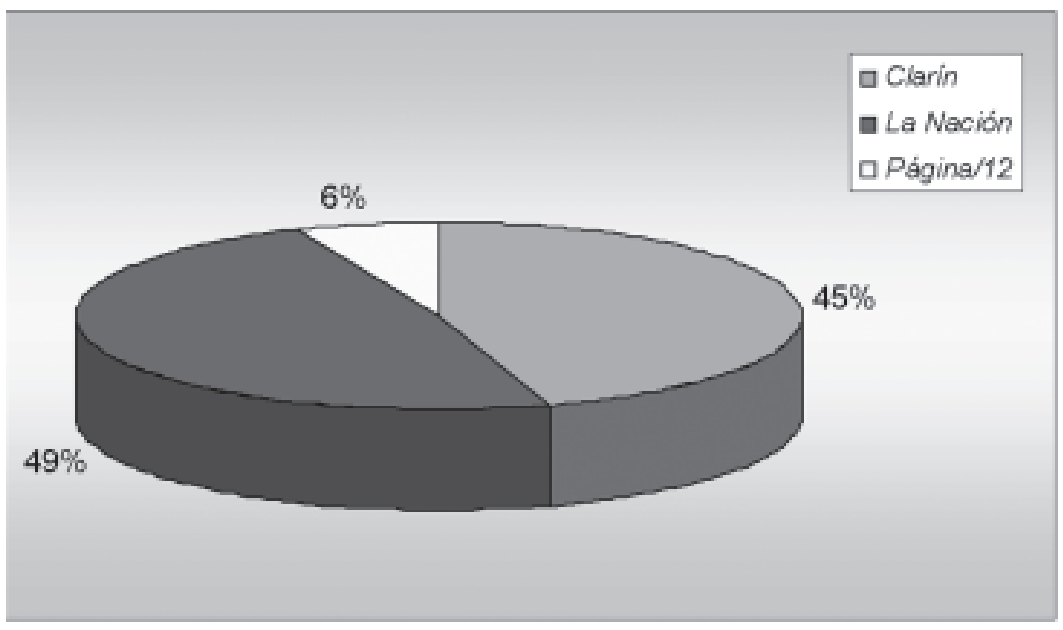

Fuente: Elaboración propia con base en datos de los diarios Clarín, La Nación y Página/12. 


\section{Gráfica XVI \\ Azul: cantidad total de notas por año}

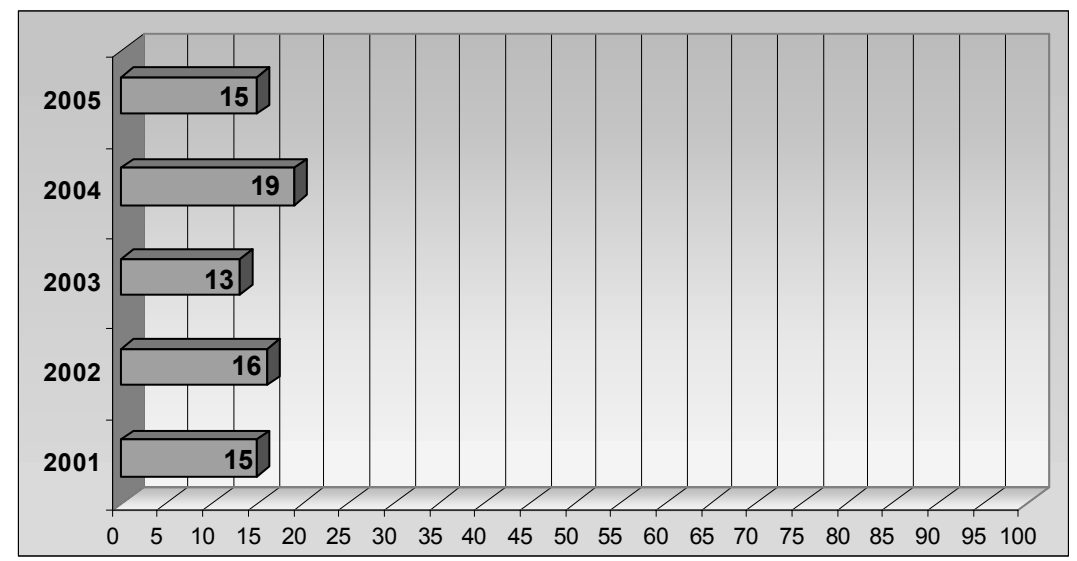

Fuente: Elaboración propia con base en datos de los diarios Clarín, La Nación y Página/12.

rior se encuentran las notas sobre actividades culturales, patrimonio histórico-cultural y ciencia y tecnología.

Como se observa al comparar las temáticas por ciudad (gráfica $\mathrm{Xx}$ ), en las tres el sector deportivo es uno de los predominantes. Sin embargo, en el ámbito turístico no sucede lo mismo. Si bien en la ciudad de Tandil es uno de los sectores más destacados junto con el deportivo, en Olavarría y Azul se mantiene en un lugar inferior. Las notas sobre economía y sociedad destacan en las tres ciudades. Patrimonio histórico-cultural y actividades culturales se muestran en un nivel inferior, siendo Tandil la ciudad con mayor cantidad de notas publicadas.

Respecto de la valoración de las noticias sobre la región (gráfica XXI), las notas positivas son las que predominan, con un crecimiento especial en 2004-2005. Entre éstas, sobresalen las relativas al turismo, resaltando lugares de las ciudades analizadas, así como el aumento de turistas en la región; las notas deportivas, sobre todo los éxitos de equipos, como personalidades destacadas a nivel nacional e internacional. Las notas de valoración negativa no representan un número significativo y hacen referencia a cuestiones de seguridad, crisis económica, especialmente en 2002, y temas delictivos particulares. 


\section{Gráfica XVII}

\section{Cantidad de notas publicadas por ciudad}

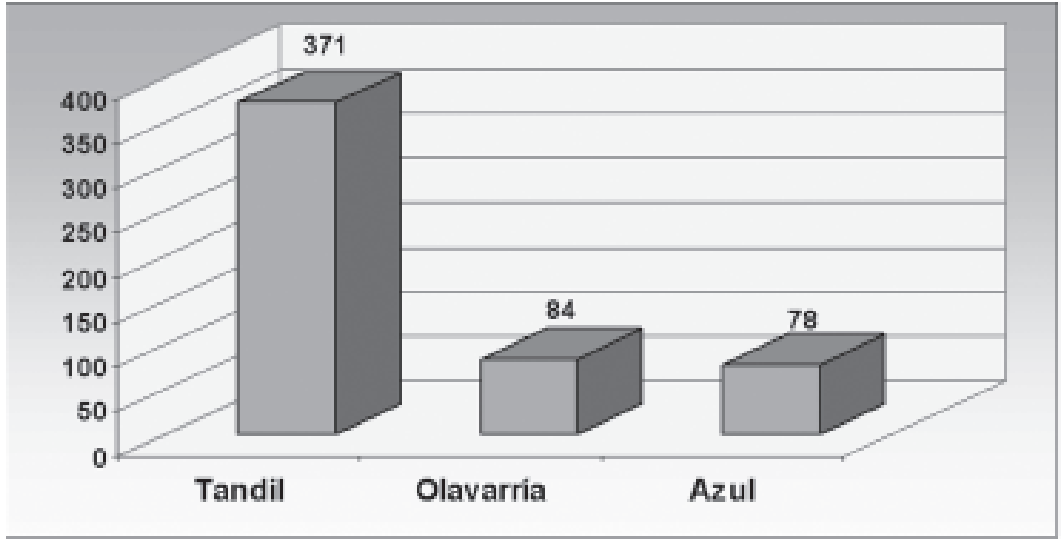

Fuente: Elaboración propia con base en datos de los diarios Clarín, La Nación y Página/12.

\section{Cantidad de notas publicadas por año (región)}

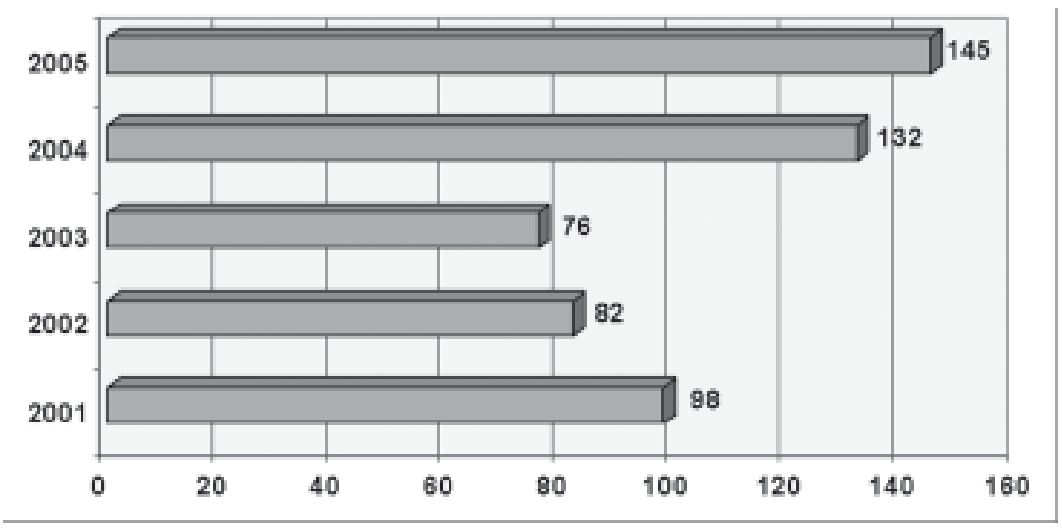

Fuente: Elaboración propia con base en datos de los diarios Clarín, La Nación y Página/12. 


\section{Gráfica XIX \\ Notas publicadas por tema y por año (región)}

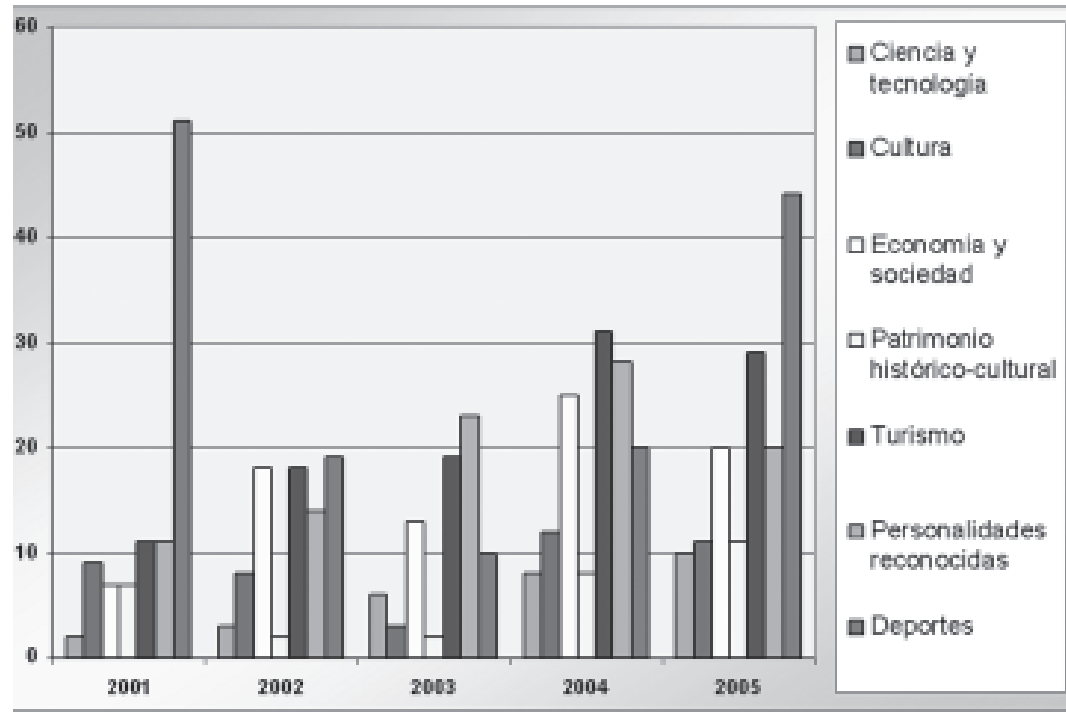

Fuente: Elaboración propia con base en datos de los diarios Clarín, La Nación y Página/12.

Gráfica XX

Notas publicadas por tema y por ciudad (2001-2005)

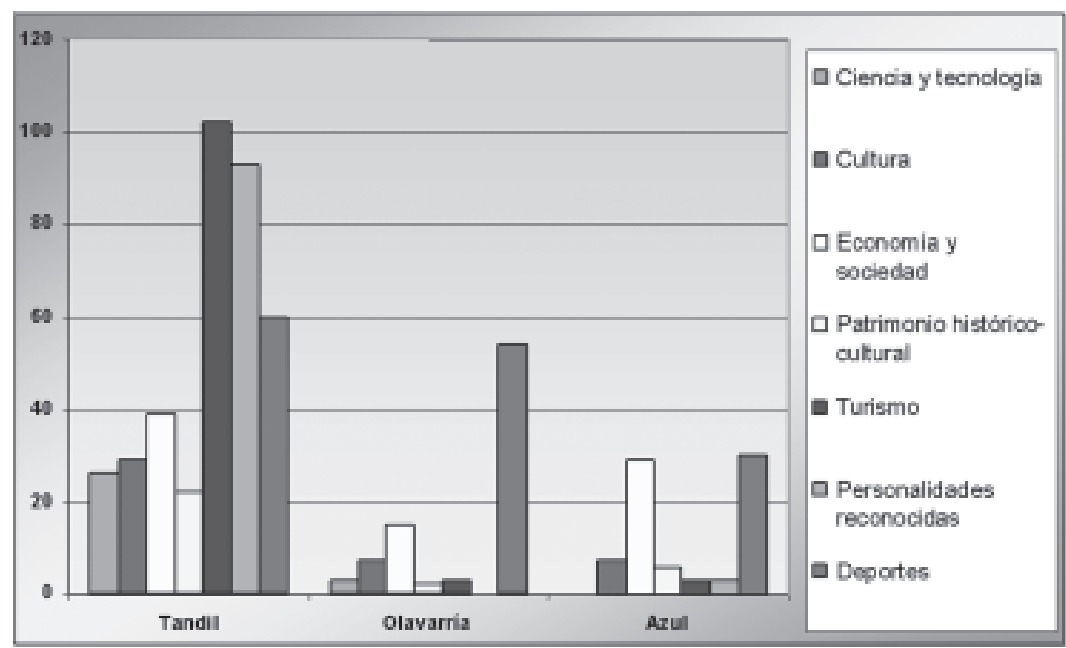

Fuente: Elaboración propia con base en datos de los diarios Clarín, La Nación y Página/12. 


\section{Gráfica XXI}

\section{Grado de valoración de notas por año (región)}
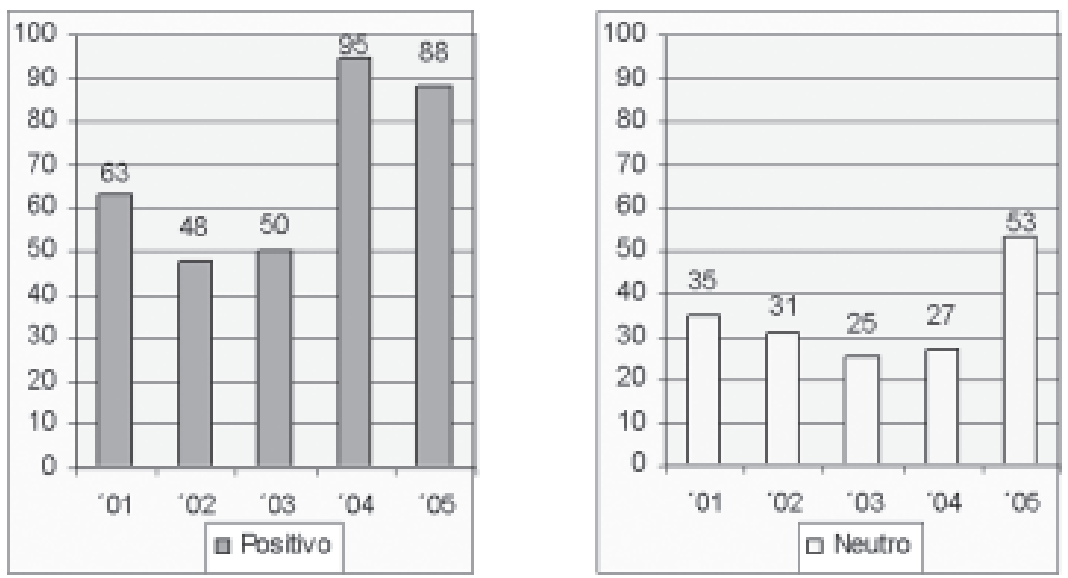

Fuente: Elaboración propia con base en datos de los diarios Clarín, La Nación y Página/12.

\section{Consideraciones finales}

En la primera parte de este trabajo buscamos demostrar que dentro del escenario internacional actual se han efectuado transformaciones que permitieron, entre otras cuestiones, la valoración de los espacios locales.

En Argentina, luego de la implementación del neoliberalismo y de sus efectos económicos, políticos y sociales marcadamente negativos, los espacios locales comenzaron a considerarse como potenciales agentes de desarrollo.

De esta manera, en los últimos años entidades subnacionales han comenzado a establecer estrategias que apuntan a lograr una inserción en el mundo global y un aprovechamiento de los beneficios que el mismo les provee. Dentro de estas estrategias de inserción y fortalecimiento de ciudades y regiones se encuentran las de imagen y comunicación, como la marca-ciudad y la marcaregional.

En general, las estrategias de marca-ciudad surgen con la finalidad de otorgar un valor agregado. Claramente, la fuerza que se le está dando a las submarcas contribuye a la intención de reposicionamiento, ya que se busca asociar al lugar en cuestión con algo más que generalidades, se busca explotar su diversidad de atractivos aprovechando al máximo los diferentes atributos. En ese sentido, la marca-ciudad se presenta como una clara alternativa para localidades como Tandil, Olavarría y Azul. 
En la segunda parte de la investigación se analizó la valoración de la imagen de la región del TOA en los grandes medios gráficos del país, con el objetivo de conocer la percepción de la prensa nacional para identificar los atributos -positivos o negativos- que se asocian con la región.

Asimismo, del análisis de la factibilidad sobre el establecimiento de marca-ciudad o marca-regional en estas ciudades surgen algunas cuestiones que es importante señalar:

- La región aparece en los diarios nacionales signada por importantes diferencias. En el periodo analizado, la ciudad de Tandil es la más nombrada y muestra un crecimiento progresivo y diversificado, ya que las notas sobre las distintas temáticas aumentaron. En cambio, las notas sobre Olavarría y Azul se mantienen estables en número a lo largo del periodo y fundamentalmente concentradas en el área deportiva.

- Los temas más frecuentes de la región son el deportivo, el turístico y el económico-social. Respecto del ámbito deportivo resulta interesante observar que en las tres ciudades es uno de los sectores más destacados, significando $41 \%$ del total de noticias publicadas sobre la ciudad de Tandil (incluido el punto personalidades reconocidas, en su gran mayoría relacionadas con el deporte), 64\% en Olavarría y 38\% en Azul. A pesar de esta coincidencia en los tres casos, se puede ver una diferencia particular. En el caso de Tandil, las noticias deportivas hacen referencia a personalidades deportivas individuales reconocidas en los ámbitos nacional e internacional, a visitas de clubes de futbol y a actividades de aventura. En los casos de Olavarría y Azul, el sector deportivo es prácticamente monotemático. Se destacan fundamentalmente los éxitos y campeonatos del equipo de baloncesto Estudiantes de Olavarría y los equipos de voleibol Olympikus y Azul Vóley.

- La ciudad de Tandil, a diferencia de Olavarría y Azul, ha sufrido un fuerte crecimiento en los últimos cinco años en los diversos ámbitos. Especialmente el sector turístico parece que ha funcionado como un disparador que produce un significativo derrame hacia el resto de los sectores.

- En el sector económico, la prensa nacional refleja en la ciudad de Tandil una diversificación importante. En Ola- 
varría y Azul el resto de los sectores analizados se mantienen de manera estable, sin reflejar cambios importantes.

- A lo largo del periodo analizado, las noticias sobre la región han ido aumentando gradualmente y ha mejorado su imagen, de acuerdo con la valoración de las notas publicadas. De todas maneras, aún no parece que se manifieste una verdadera percepción de región, dado que la prensa nacional hace mención de cada ciudad en particular, las notas muestran importantes diferencias en temas y números de notas y son pocas las noticias que hacen referencia a la región en general.

Como última reflexión podemos afirmar que la región figura en la prensa nacional con una valoración significativamente positiva. En general, las notas publicadas resaltan, destacan e informan determinadas características de las ciudades de la región analizada, lo que resulta clave para comenzar a trabajar en torno a la implementación de una marca-regional.

\section{Bibliografía}

Agüero, Julio, Katheryn Brea y Julissa Mirabal (2006), Análisis de las potencialidades de la ciudad de Santo Domingo de Guzmán para la construcción de su marca-ciudad, Universidad APEC, Santo Domingo.

Arocena, José (2001), “Globalización, integración y desarrollo local. Apuntes para la elaboración de un marco conceptual”, En Óscar Madoery y A. Vázquez Barquero (eds.), Transformaciones globales, instituciones y politicas de desarrollo local, Homo Sapiens, Rosario.

Boisier, Sergio (2005), “¿Hay espacio para el desarrollo local en la globalización?, Revista de la CEPAL, 86, Santiago de Chile, pp. 47-62.

Colombo, Sandra (2006), "Políticas públicas de inserción internacional. Oportunidades para Argentina en un mundo en transformación”, en CEIPIL (comp.), Programa Estado, desarrollo y políticas públicas, UNCPBA, Tandil. 
Gilles, Brettón (1994), "La globalización y el Estado: algunos conceptos teóricos", en Mario Rapoport (ed.), Globalización, integración e identidad nacional, GEL, Buenos Aires.

Madoery, Óscar (1999), El territorio como factor estratégico de desarrollo. Hacia un espacio de gestión metropolitana en el Gran Rosario, Homo Sapiens, Rosario.

Management Político (2004), "Construcción de la Marca-Ciudad de Villa Gesell, Provincia de Buenos Aires, Argentina”, ponencia presentada ante el Congreso Internacional de City Marketing, Elche.

Petrantonio, Marcela (2003), "Innovando en la gestión local: la importancia de definir una política exterior local”, en Anales del v Seminario Nacional de Redmuni, Mendoza.

Presidencia de la Nación (2004), Documento fundacional: marca argentina, Secretaría de Medios de Comunicación-Secretaría de Turismo, Buenos Aires.

Torrado, Susana (1999), "La pobreza, según se mide", diario Clarín (digital), www.clarin.com, enero de 2004.

\section{Sitios Web:}

Marca Argentina: www.marcaargentina.gov.ar/.

Diario Clarin (digital): www.clarin.com.

Diario La Nación (digital): www.lanacion.com.

Diario Pagina/12 (digital): www.pagina12.com.

Recibido: 5 de junio de 2007. Aceptado: 29 de abril de 2008.

Mariana Calvento. Es licenciada en relaciones internacionales por la Facultad de Ciencias Humanas (FCH) de la Universidad Nacional del Centro de la Provincia de Buenos Aires (UNCPBA). Actualmente realiza estudios de posgrado en la maestría en desarrollo local en la Universidad Nacional San Martín-Universidad Autónoma de Madrid (unsam-UAM), Buenos Aires. Desarrolla tareas de docencia como ayudante diplomado interino de la li- 
cenciatura en relaciones internacionales, y de investigación como auxiliar de investigación en el Centro de Estudios Interdisciplinarios, Problemas Internacionales y Locales (CEIPIL) de la FCH-UNСРВА. Su línea de investigación es estado, desarrollo y políticas públicas. Entre sus publicaciones destacan: Profundización de la pobreza en América Latina. El caso de Argentina 1995-1999, ed. electrónica, EUMED (2007), texto completo en www.eumed.net/ libros/2007a/; "Fundamentos teóricos del neoliberalismo: su vinculación con las temáticas sociales y sus efectos en América Latina", Convergencia, 41, Universidad Autónoma del Estado de México, Toluca, México (2006); "Pobreza en América Latina: la experiencia argentina en la década de 1990", Scripta Nova, x(212), revista electrónica de geografía y ciencias sociales, Universidad de Barcelona, Barcelona (2006), http://www.ub.es/geo$\mathrm{crit} / \mathrm{sn} / \mathrm{sn}-212 . \mathrm{htm}$.

Maia Ochoteco. Es estudiante avanzada de la licenciatura en relaciones internacionales de la Facultad de Ciencias Humanas (FCH) de la Universidad Nacional del Centro de la Provincia de Buenos Aires (UNCPBA). Ha trabajado como docente en la licenciatura en relaciones internacionales de la UNCPBA y como investigadora becaria de la Comisión de Investigaciones Científicas del Gobierno de la Provincia de Buenos Aires, Programa Formatec III. 